\title{
The long-term survival outcomes of gastric cancer patients with total intravenous anesthesia or inhalation anesthesia: a single-center retrospective cohort study
}

Wei-Wei Wu ${ }^{1 \dagger}$, Wei-Han Zhang ${ }^{2 \dagger}$, Wei-Yi Zhang ${ }^{1}$, Kai Liu ${ }^{2}$, Xin-Zu Chen², Zong-Guang Zhou ${ }^{2}$, Jin Liu', Tao $\mathrm{Zhu}^{1+}$ and Jian-Kun Hu${ }^{2^{*}+}$

\begin{abstract}
Background: The relationship between the type of anesthesia and the survival outcomes of gastric cancer patients is uncertain. This study compared the overall outcome of gastric cancer patients after surgery with total intravenous anesthesia (TIVA) or inhalation anesthesia (IHA).

Methods: Clinicopathological variables of gastric cancer patients were retrieved from the database of the Surgical Gastric Cancer Patient Registry in West China Hospital, Sichuan University. Patients were grouped according to whether they received TIVA or IHA during the operation. Propensity score (PS) matching was used to balance the baseline variables, and survival outcomes were compared between these two groups. In addition, studies comparing survival outcomes between TIVA and IHA used for gastric cancer surgery and published before April 20th, 2020, were identified, and their data were pooled.

Results: A total of 2827 patients who underwent surgical treatment from Jan 2009 to Dec 2016 were included. There were 323 patients in the TIVA group and 645 patients in the IHA group, with 1:2 PS matching. There was no significant difference in overall survival outcomes between the TIVA and IHA groups before matching the cohort ( $p=0.566)$ or after matching the cohort $(p=0.679)$ by log-rank tests. In the Cox hazard regression model, there was no significant difference between the TIVA and IHA groups before (HR: 1.054, 95\% CI: $0.881-1.262, p=0.566$ ) or after (HR: $0.957,95 \% \mathrm{Cl}: 0.779-1.177, p=0.679)$ PS matching. The meta-analysis of survival outcomes between the TIVA and IHA groups found critical statistical value in the before PS matching cohort (HR 0.74, 95\% Cl: 0.57-0.96 $p<0.01)$ and after PS matching cohort (HR: 0.65, 95\% Cl: 0.46-0.94, p < 0.01).
\end{abstract}

\footnotetext{
* Correspondence: hujkwch@126.com

${ }^{+}$Wei-Wei Wu and Wei-Han Zhang contributed equally to this work.

${ }^{\dagger}$ Tao Zhu and Jian-Kun Hu jointly supervised this work.

2Department of Gastrointestinal Surgery and Laboratory of Gastric Cancer, State Key Laboratory of Biotherapy, West China Hospital, Sichuan University, and Collaborative Innovation Center for Biotherapy, No. 37 Guo Xue Street, Chengdu, Sichuan Province, China

Full list of author information is available at the end of the article
}

(C) The Author(s). 2021 Open Access This article is licensed under a Creative Commons Attribution 4.0 International License, which permits use, sharing, adaptation, distribution and reproduction in any medium or format, as long as you give appropriate credit to the original author(s) and the source, provide a link to the Creative Commons licence, and indicate if changes were made. The images or other third party material in this article are included in the article's Creative Commons. licence, unless indicated otherwise in a credit line to the material. If material is not included in the article's Creative Commons licence and your intended use is not permitted by statutory regulation or exceeds the permitted use, you will need to obtain permission directly from the copyright holder. To view a copy of this licence, visit http://creativecommons.org/licenses/by/4.0/ The Creative Commons Public Domain Dedication waiver (http://creativecommons.org/publicdomain/zero/1.0/) applies to the data made available in this article, unless otherwise stated in a credit line to the data. 
Conclusions: Combined with the results of previous studies, total intravenous anesthesia has been shown to be superior to inhalation anesthesia in terms of overall survival for gastric cancer patients undergoing surgical treatment. The selection of intravenous or inhalation anesthesia for gastric cancer surgery should take into account the long-term prognosis of the patient.

Keywords: Gastric cancer, Anesthesia, Intravenous, Inhalation, Prognosis

\section{Introduction}

Gastric cancer is one of the most common malignant diseases of the digestive system, especially in East Asian countries [1,2]. Radical surgical treatment with perioperative chemotherapy is the major treatment choice according to the latest treatment guidelines [3, 4]. Several clinicopathological variables, such as macroscopic type, Lauren classification, differentiation degree of the tumor, tumor stage, resection degree, resection patterns, and lymphadenectomy degree, are independent prognostic factors of gastric cancer patients $[5,6]$.

In the perioperative period, both surgical stress and anesthetics may influence cell-mediated immunity and humoral immunity by influencing the functions of immune competent cells and inflammatory mediator secretion, resulting in immunosuppression. Meanwhile, immunosuppression attributable to anesthetics may accelerate the growth and metastases of cancer cells and result in poor survival of patients with malignant diseases [7]. In addition, anesthetics were found to suppress the activity of natural killer cells and promote tumor metastasis in rat models [8]. Anesthetics can also result in immunological suppression by influencing the function of natural killer cells, as shown in a clinical study of breast cancer patients [9].

Specifically, propofol-based total intravenous anesthesia has been found to have fewer immunosuppressive effects than sevoflurane-based or desfluranebased inhalation anesthesia. Previous studies have shown that survival outcomes are significantly better in prostate cancer and colon cancer patients who receive propofol-based total intravenous anesthesia than in those who receive desflurane-based inhalation anesthesia $[10,11]$. However, the debate regarding the influence of anesthesia types on the long-term survival outcomes of patients with malignant disease has not been settled. For example, some studies reported no relevance of the type of anesthesia for the prognosis of patients with breast cancer [12, 13]. However, paradoxical survival outcomes have been reported between total intravenous anesthesia and inhalation anesthesia in gastric cancer patients [14-16].

Therefore, we performed this single-center retrospective cohort study with a large sample size and adjusted for the clinicopathological prognostic characteristics by the propensity score (PS) matching method between total intravenous anesthesia (TIVA) and inhalation anesthesia (IHA). The purpose of this study was to assess the relationship between types of anesthesia and long-term overall survival outcomes after gastric cancer surgery.

\section{Methods \\ Data available}

We collected data from the database of the Surgical Gastric Cancer Patient Registry in West China Hospital with the registration number WCH-SGCPR-2020. The establishment of this database was approved by the Biomedical Ethical Committee of the West China Hospital, Sichuan University, China (No. 2014-215). Patient records and personal information were deidentified before statistical analysis.

Patients who underwent surgical treatment from Jan 1st, 2009 to Dec 31st, 2016 in the WCH-SGCPR database were screened $[17,18]$. We included primary gastric cancer patients who underwent surgical resection, with complete intraoperative anesthesia information and postoperative follow-up information (updated to Jan 1st, 2020). Patients with a history of other malignant diseases, preoperative chemotherapy or radiotherapy were excluded from the present study. The selection of the patients is presented in Fig. 1.

\section{Anesthesia method}

The choice of anesthesia type was determined by the characteristics of the patients and the preference of the responsible anesthesiologists, and usually choose the type they are better at. In the present study, the patients were divided into the TIVA group and the IHA anesthesia group according to the anesthesia methods. In both the TIVA and IHA groups, anesthesia was induced with midazolam $0.05-0.15 \mathrm{mg} /$ $\mathrm{kg}, \quad 0.3 \mu \mathrm{g} / \mathrm{kg}$ sufentanil, and $1-2.5 \mathrm{mg} / \mathrm{kg}$ propofol. The maintenance dose of anesthesia was propofol 3 $\mathrm{mg} /\left(\mathrm{kg}^{*} \mathrm{~h}\right)$ or sevoflurane $1 \sim 2 \%$ and remifentanil 0.1 $\sim 0.2 \mu \mathrm{g} /\left(\mathrm{kg}^{*} \mathrm{~min}\right)$. For patients with total intravenous anesthesia, anesthesia was maintained with propofol and remifentanil infusion. For patients with inhalation anesthesia, anesthesia was maintained with sevoflurane or desflurane inhalation and remifentanil infusion. Patient-controlled analgesia was recommended for all gastric cancer patients who underwent surgical 


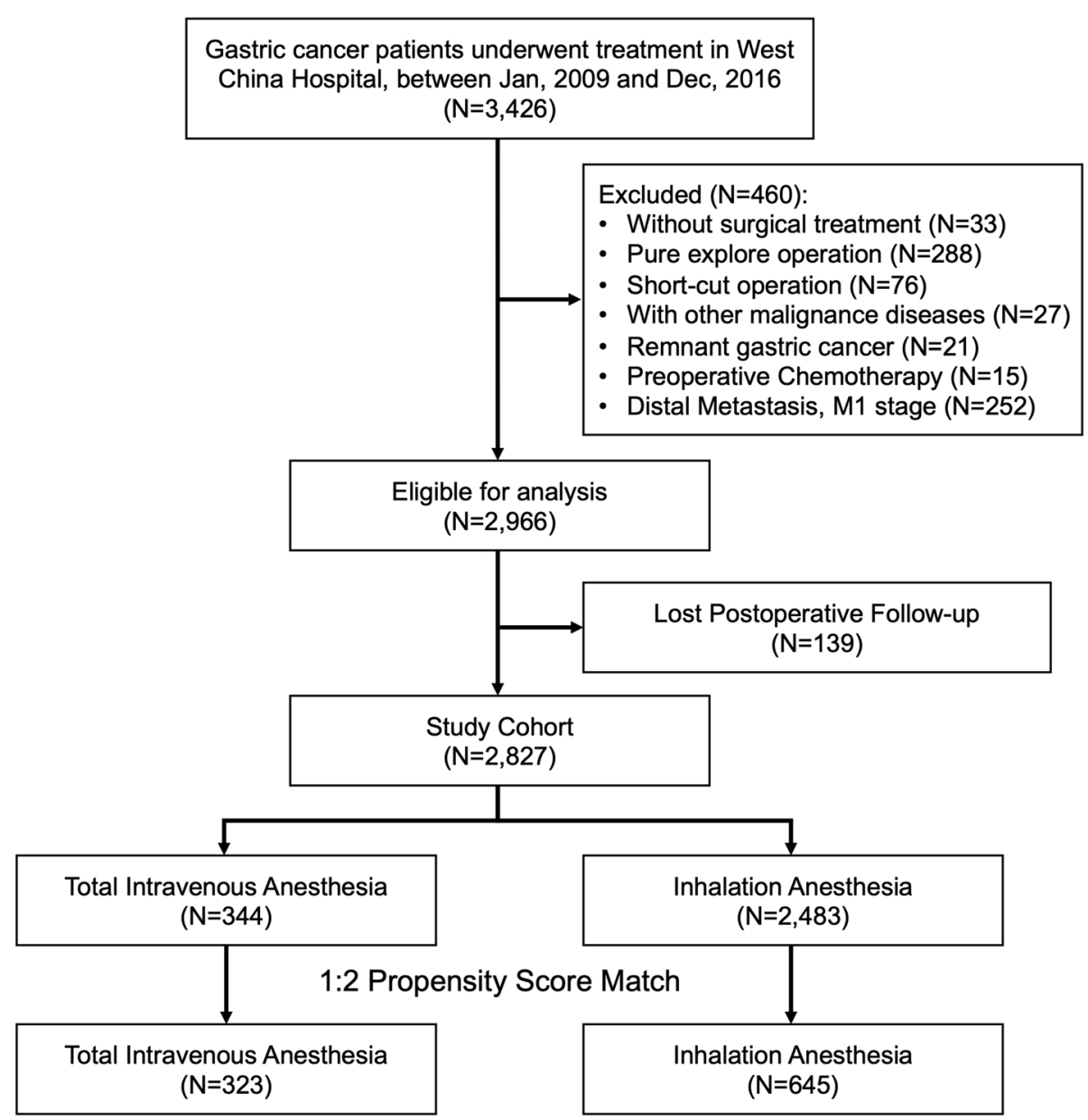

Fig. 1 Flow chart of patients' selection

treatment in our hospital and they received a total dose of $3 \mu \mathrm{g} / \mathrm{mL}$ fentanyl or $0.5 \mu \mathrm{g} / \mathrm{mL}$ sufentanil for $72-120 \mathrm{~h}$ postoperatively. Nonsteroidal antiinflammatory drugs (NSAIDs), flurbiprofen axetil or parecoxib sodium were used as rescue solutions during the postoperative recovery period and the hospital stay.

\section{Surgical treatment method}

All of the included patients underwent surgical treatment in the Department of Gastrointestinal Surgery, West China Hospital, Sichuan University. A radical operation with curative intent was performed according to the Japanese Gastric Cancer Treatment Guidelines [3]. Total or subtotal gastrectomy was performed according to the tumor stage, tumor location and status of the regional lymph nodes. Intraoperative frozen sections were routinely performed to secure safe resection margins. There were no limitations on the reconstruction methods.

\section{Clinicopathological characteristics}

The following clinicopathological information was also retrieved from the database: age (years), sex (male or female), tumor size $(\mathrm{cm})$, Borrmann type (Type I-IV), differentiation degree (well, moderate, poor and undifferentiated), tumor location (adenocarcinoma of the esophagogastric junction (AEG) and non-AEG), operation type (laparoscopic surgery and open surgery), radical degree ( $R 0, R 1$, and $R 2$ ), lymphadenectomy degree (D1, D1+, D2, and D2+), operation time (minutes), blood loss $(\mathrm{ml})$, pathological tumor stage (pT, $\mathrm{pN}$ and $\mathrm{pTNM}$ ), number of positive and examined lymph nodes, postoperative nonsteroidal antiinflammatory drug (NSAID) use, adjuvant chemotherapy and postoperative recovery course (complications and hospital stay). For the clinicopathological variables, the pathological examination was performed by pathologists of the Department of West China Hospital, Sichuan University according to the AJCC 8th staging manual [19]. 


\section{Follow-up information}

Postoperative follow-up was scheduled for each gastric cancer patient who underwent treatment in our department. We recommended at least two outpatient followups in the first 3 years and at least one outpatient follow-up in subsequent years. At each outpatient visit, a physical examination, serum tumor markers (CEA, CA19-9, CA125, CA72-4), and enhanced computed tomography (chest and abdominal) were essential tests. Follow-up information was updated to Jan 1st, 2020. The main reasons for patients lost to follow-up were refused to attend the outpatient visits or changes in contact information. Of the 2966 patients eligible for analysis, 139 patients were lost to postoperative followup, so the follow-up rate was $95.3 \%(2827 / 2966)$, with a 48.8 (23.3-77.4) month median follow-up duration.

\section{Meta-analysis between intravenous and inhalation anesthesia methods of gastric cancer surgery}

A comprehensive literature search was performed in the Cochrane Library (January 1, 2005 to November 25, 2020), MEDLINE via PubMed (January 1, 1966 to November 25, 2020) and EMBASE (January 1, 1974 to December 02, 2020) using the terms "gastric cancer", "gastric carcinoma", "gastric neoplasm", "stomach cancer", "stomach carcinoma", "stomach neoplasm", "inhalation, anesthesia", "insufflation", "volatile", "intravenous, anesthesia", "infusion", "surgery" and "operation". Previously published metaanalyses and systematic reviews were also searched for relevant articles. Relevant articles were also retrieved by manually checking the reference lists of the retrieved articles. Titles, abstracts, and subsequently full-text articles were screened by two authors (WW Wu and WH Zhang). We only included studies comparing survival outcomes between total intravenous anesthesia and inhalation anesthesia methods of gastric cancer surgery. Review articles, case reports, articles in languages other than English, and articles with incomplete or duplicated data were excluded.

Data from the included studies were independently extracted by two authors (WH Zhang, WW Wu). For each study, we recorded the name of the first author, year of publication, country, study design, and period of the included patients. The following variables were also extracted: age (mean $\pm \mathrm{SD})$, sex, tumor stage and survival outcomes (hazard ratio, HR; 95\% confidence intervals, 95\% CI). The meta-analysis of survival outcomes was performed by the random-effects method according to the Cochrane guidelines. We evaluated all included studies for quality with the NewcastleOttawa Scale (NOS), and all studies were rated a minimum of 5 points.

\section{Statistical analysis}

Continuous variables with a non-normal distribution are expressed as the median and interquartile range (IQR, 25-75\%); categorical variables are expressed as numbers (\%). The Mann-Whitney $U$ test was used to analyze continuous variables and ordinal categorical variables, whereas the chi-square test was used for unordered categorical variables. Variables that yielded $p<0.1$ in univariate survival analysis were considered candidates in the multivariate Cox-hazard model. A $P$ value $<0.05$ (2sided) was defined as statistically significant.

For patients in the TIVA group, propensity scores were computed as the conditional probability using a logistic regression model that included baseline characteristics (age, sex, tumor location, operation type, radical degree, lymphadenectomy degree, $\mathrm{pT}$ stage, $\mathrm{pN}$ stage, pM stage, and adjuvant chemotherapy) to achieve balance in covariates between the TIVA and IHA groups. Propensity score matching pairs were identified without replacement using a 1:2 nearest neighbor matching algorithm with caliper width determined by the recommendation (0.001 of the standard deviation of the logit) [20]. The balance of covariates between the TIVA and IHA groups was assessed by the standardized mean difference (SMD). An $\mathrm{SMD}<0.1$ indicated a good balance in the covariates between the two groups. All statistical analyses were conducted using R Software (http://www.Rproject.org/), including the "survival", "survminer", "ggplot2", "nonrandom", "MatchIt", "meta" and "metafor" packages.

Considering that this is a retrospective study, we calculated the statistical power via PASS 11 (Version 11.0.7).

\section{Results}

Patient characteristics before and after propensity score matching

A total of 3426 patients underwent treatment in the Department of Gastrointestinal Surgery, West China Hospital, Sichuan University from January 2009 to December 2016. According to the inclusion criteria and exclusion criteria, 2827 patients were included in the final analysis, 344 patients with total intravenous anesthesia were in the TIVA group, and 2483 patients with inhalation anesthesia were in the IHA group. The clinicopathological and intraoperative characteristics of the patients were compared between the TIVA and IHA groups before and after propensity score matching, and the results are presented in Table 1. Before PS matching, tumor size, operation type, radical degree, blood loss, pTNM stage, numbers of examined, positive lymph nodes were unbalanced between the TIVA and IHA groups $(p<0.05$ and SMD $>0.1)$. After the 1:2 PS matching procedures, 323 patients in the TIVA group 
Table 1 Clinicopathological characteristics between TIVA group and IHA group, before and after propensity-score match

\begin{tabular}{|c|c|c|c|c|c|c|c|c|c|}
\hline Characteristics & & $\begin{array}{l}\text { TIVA group } \\
N=323(\%)\end{array}$ & $\begin{array}{l}\text { IHA group } \\
N=2264(\%)\end{array}$ & $\begin{array}{l}P \\
\text { value }\end{array}$ & SMD & $\begin{array}{l}\text { TIVA group } \\
N=344(\%)\end{array}$ & $\begin{array}{l}\text { IHA group } \\
N=688(\%)\end{array}$ & $\begin{array}{l}P \\
\text { value }\end{array}$ & SMD \\
\hline Age, median (IQR) & Years & $60.0[51.0,66.0]$ & $\begin{array}{l}59.00[50.0, \\
66.0]\end{array}$ & 0.628 & 0.035 & $60.0[51.0,66.0]$ & $60.0[51.0,67.0]$ & 0.967 & 0.018 \\
\hline Gender & Female & $102(31.6)$ & $671(29.6)$ & 0.517 & 0.042 & 102 (31.6) & 205 (31.8) & 1 & 0.004 \\
\hline Tumor Size, median (IQR) & $\mathrm{cm}$ & $4.0[3.0,6.0]$ & $5.0[3.0,6.0]$ & 0.012 & 0.152 & $4.0[3.0,6.0]$ & $4.0[3.0,6.0]$ & 0.435 & 0.065 \\
\hline Borrmann Type & Type III-IV & $131(40.6)$ & $916(40.5)$ & 1 & 0.002 & $131(40.6)$ & $238(36.9)$ & 0.301 & 0.075 \\
\hline Differentiated Degree & G3-G4 & $260(80.5)$ & $1812(80.0)$ & 0.905 & 0.012 & $260(80.5)$ & $521(80.8)$ & 0.986 & 0.007 \\
\hline Tumor Location & Non-AEG & $74(22.9)$ & $619(27.3)$ & 0.106 & 0.102 & $74(22.9)$ & $145(22.5)$ & 0.945 & 0.010 \\
\hline Operation Type & Laparoscopic & $29(9.0)$ & $318(14.0)$ & 0.016 & 0.159 & $29(9.0)$ & $73(11.3)$ & 0.314 & 0.078 \\
\hline Radical Degree & $\mathrm{R} 1 / \mathrm{R} 2$ & $4(1.2)$ & $103(4.5)$ & 0.008 & 0.198 & $4(1.2)$ & $6(0.9)$ & 0.912 & 0.03 \\
\hline Lymphadenectomy Degree & $\mathrm{D} 2 / \mathrm{D} 2+$ & $291(90.1)$ & $1991(87.9)$ & 0.303 & 0.069 & $291(90.1)$ & $580(89.9)$ & 1 & 0.006 \\
\hline Operation Time, median (IQR) & $\min$ & $\begin{array}{l}230.0[205.0, \\
260.0]\end{array}$ & $\begin{array}{l}235.0[205.0, \\
270.0]\end{array}$ & 0.368 & 0.067 & $\begin{array}{l}230.0[205.0, \\
260.0]\end{array}$ & $\begin{array}{l}230.0[200.0, \\
265.0]\end{array}$ & 0.928 & 0.007 \\
\hline Blood Loss, median (IQR) & $\mathrm{ml}$ & $\begin{array}{l}\text { 100.0 [50.0, } \\
105.0]\end{array}$ & $\begin{array}{l}100.0[80.0, \\
150.0]\end{array}$ & 0.032 & 0.147 & $\begin{array}{l}\text { 100.0 [50.0, } \\
105.0]\end{array}$ & $\begin{array}{l}100.0[80.0, \\
200.0]\end{array}$ & 0.088 & 0.126 \\
\hline \multirow[t]{4}{*}{ pT stage } & $\mathrm{T} 1$ & $68(21.1)$ & $491(21.7)$ & 0.242 & 0.120 & $68(21.1)$ & $140(21.7)$ & 0.515 & 0.102 \\
\hline & $\mathrm{T} 2$ & $57(17.6)$ & $328(14.5)$ & & & 57 (17.6) & $126(19.5)$ & & \\
\hline & T3 & $73(22.6)$ & $460(20.3)$ & & & $73(22.6)$ & $120(18.6)$ & & \\
\hline & $\mathrm{T} 4$ & $125(38.7)$ & $985(43.5)$ & & & $125(38.7)$ & $259(40.2)$ & & \\
\hline \multirow[t]{4}{*}{ pN stage } & No & $126(39.0)$ & $771(34.1)$ & 0.125 & 0.143 & $126(39.0)$ & $256(39.7)$ & 0.917 & 0.048 \\
\hline & N1 & $60(18.6)$ & $372(16.4)$ & & & $60(18.6)$ & $108(16.7)$ & & \\
\hline & N2 & $52(16.1)$ & $417(18.4)$ & & & $52(16.1)$ & $106(16.4)$ & & \\
\hline & N3 & $85(26.3)$ & $704(31.1)$ & & & $85(26.3)$ & $175(27.1)$ & & \\
\hline \multirow[t]{3}{*}{ pTNM stage } & । & $92(28.5)$ & $575(25.4)$ & 0.026 & 0.161 & $92(28.5)$ & $189(29.3)$ & 0.962 & 0.019 \\
\hline & $\|$ & $91(28.2)$ & $529(23.4)$ & & & $91(28.2)$ & $178(27.6)$ & & \\
\hline & III & $140(43.3)$ & $1160(51.2)$ & & & $140(43.3)$ & $278(43.1)$ & & \\
\hline No. of Positive LNs, median (IQR) & numbers & $2.0[0.0,7.0]$ & $2.0[0.0,8.0]$ & 0.013 & 0.138 & $2.0[0.0,7.0]$ & $2.0[0.0,7.0]$ & 0.806 & 0.034 \\
\hline $\begin{array}{l}\text { No. of Examined LNs, median } \\
\text { (IQR) }\end{array}$ & numbers & $26.0[19.5,35.0]$ & $27.0[20.0,37.0]$ & 0.065 & 0.159 & $26.0[19.5,35.0]$ & $26.0[20.0,36.0]$ & 0.670 & 0.066 \\
\hline Perioperative NSAIDs & Use & $6(1.9)$ & $57(2.5)$ & 0.598 & 0.045 & $6(1.9)$ & $16(2.5)$ & 0.701 & 0.043 \\
\hline Adjuvant Chemotherapy & Yes & $183(56.7)$ & $1370(60.5)$ & 0.207 & 0.078 & $183(56.7)$ & $377(58.4)$ & 0.643 & 0.036 \\
\hline $\begin{array}{l}\text { Postoperative 30-day } \\
\text { complications }\end{array}$ & Yes & $54(16.7)$ & $411(18.2)$ & 0.582 & 0.038 & $54(16.7)$ & $114(17.7)$ & 0.779 & 0.025 \\
\hline $\begin{array}{l}\text { Postoperative Hospital Stay, } \\
\text { median (IQR) }\end{array}$ & Days & $\begin{array}{l}10.00[9.00 \\
12.00]\end{array}$ & $\begin{array}{l}10.00[9.00 \\
12.00]\end{array}$ & 0.992 & 0.031 & $\begin{array}{l}10.00[9.00 \\
12.00]\end{array}$ & $\begin{array}{l}10.00[9.00 \\
12.00]\end{array}$ & 0.833 & 0.015 \\
\hline
\end{tabular}

Abbreviations: TIVA Total intravenous anesthesia, IHA Inhalation anesthesia, SMD Standardized mean difference, IQR Interquartile range, AEG Adenocarcinoma of esophagogastric junction, LNs Lymph nodes

and 645 patients in the IHA group had balanced clinicopathological covariates $(p>0.05$ and $\mathrm{SMD} \leq 0.1)$. The standardized differences and distribution of the clinicopathological characteristics before and after propensity score matching are shown in Fig. 2.

\section{Univariate and multivariate survival analysis}

First, we evaluated the survival outcomes between the TIVA and IHA groups, and there was no survival difference by the log-rank test between the TIVA and IHA groups before PS matching (HR: 1.054, 95\% CI: 0.881-
1.262, $p=0.566$ ) and after PS matching (HR: 0.957, 95\% CI: 0.779-1.177, $p=0.679$ ) (Figs. 3 and 4).

Univariate and multivariate survival analyses of patients in the before and after PS matching cohorts were analyzed and are presented in Tables 2 and 3, respectively. In the multivariate survival analysis of before propensity score matching cohorts, age, tumor size, macroscopic type, radical degree, pathological TNM stage, and postoperative adjuvant chemotherapy were independent prognostic risk factors for overall survival. Additionally, in the multivariate survival analysis of 


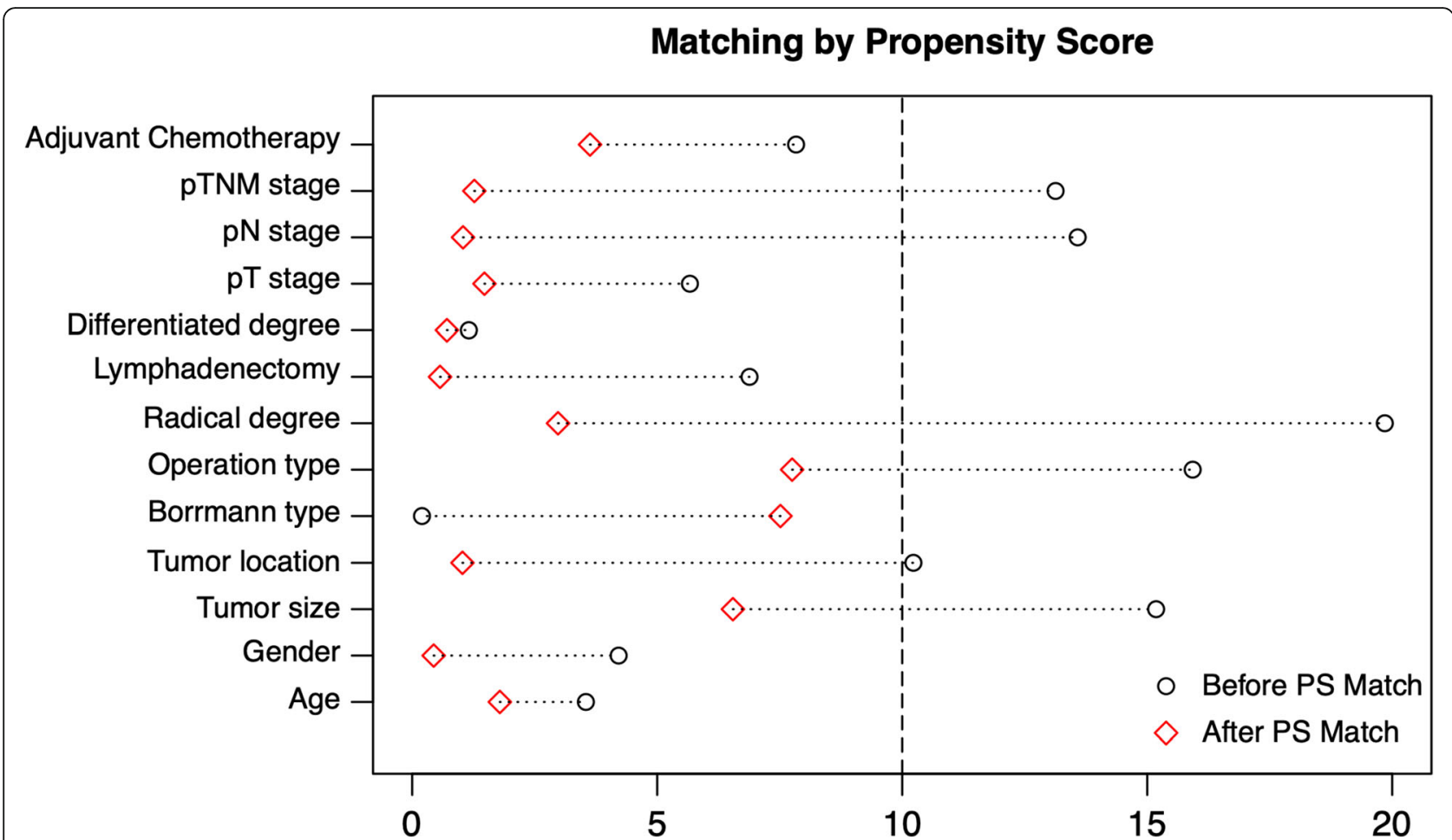

Fig. 2 Illustration of standardized differences in clinicopathological characteristics before and after propensity-score matching cohorts

patients after the propensity score matching cohort, age, tumor size, radical degree, pathological TNM stage, and adjuvant chemotherapy were independent prognostic risk factors for the overall survival outcomes. Most importantly, the anesthesia type (intravenous anesthesia or inhalation anesthesia methods) was not a significant risk factor for overall survival outcomes in either the before (HR: $1.054,95 \%$ CI: $0.881-1.262, p=0.566$ ) or after propensity score matching cohorts (HR: 0.957, 95\% CI: 0.779-1.177, $p=0.679$ ).

\section{Subgroup analysis}

We performed subgroup analyses on patients based on their final pathological stage. Patients in both the TIVA and IHA groups had similar survival rates across pTNM stages (Figs. 3 and 4). Before PS match, for whole pTNM stage, the HR was 1.054 (95\%CI: 0.881-1.262), the propensity score-adjusted HR was 0.957 (95\%CI: 0.779-1.177). For pTNM-I, the HR was 0.980 (95\%CI: $0.556-1.728)$, the propensity scoreadjusted HR was 0.630 (95\%CI: 0.442-1.639). For pTNM-II, the HR was 0.369 (95\%CI: 0.577-1.226), the propensity score-adjusted HR was 1.101 (95\%CI: 0.727-1.667). For pTNM-III, the HR was 0.995 (95\%CI: $0.798-1.240)$, the propensity score-adjusted HR was 0.901 (95\%CI: 0.697-1.164).
Meta-analysis between total intravenous and inhalation anesthesia

Through the literature search, we found three published studies that compared the survival outcomes between the TIVA and IHA groups (Supplementary Fig. 1). Meanwhile, we added the survival outcomes of our study to the meta-analysis. The general characteristics of the studies are presented in Table 4. Both of the studies used the propensity score matching method to balance the clinicopathological characteristics between the TIVA and IHA groups. Therefore, a meta-analysis of survival outcomes was performed before and after PS matching (Fig. 5A and B). A critical statistical value was found in the before (HR 0.74, 95\% CI: 0.57-0.96, $p<0.01$ ) and after (HR 0.65, 95\% CI: 0.46-0.94, p < 0.01) PS matching cohort between the TIVA and IHA groups.

\section{Discussion}

According to previous studies, conflicting conclusions have been reported on the survival outcomes of total intravenous anesthesia and inhalation anesthesia used during gastric cancer surgery [14-16]. However, in both the before PS matching and after PS matching cohorts, there was no significant difference between TIVA and IHA in the overall survival outcomes of patients who underwent gastric cancer surgery. In the further subgroup analysis, no statistical differences were found in 

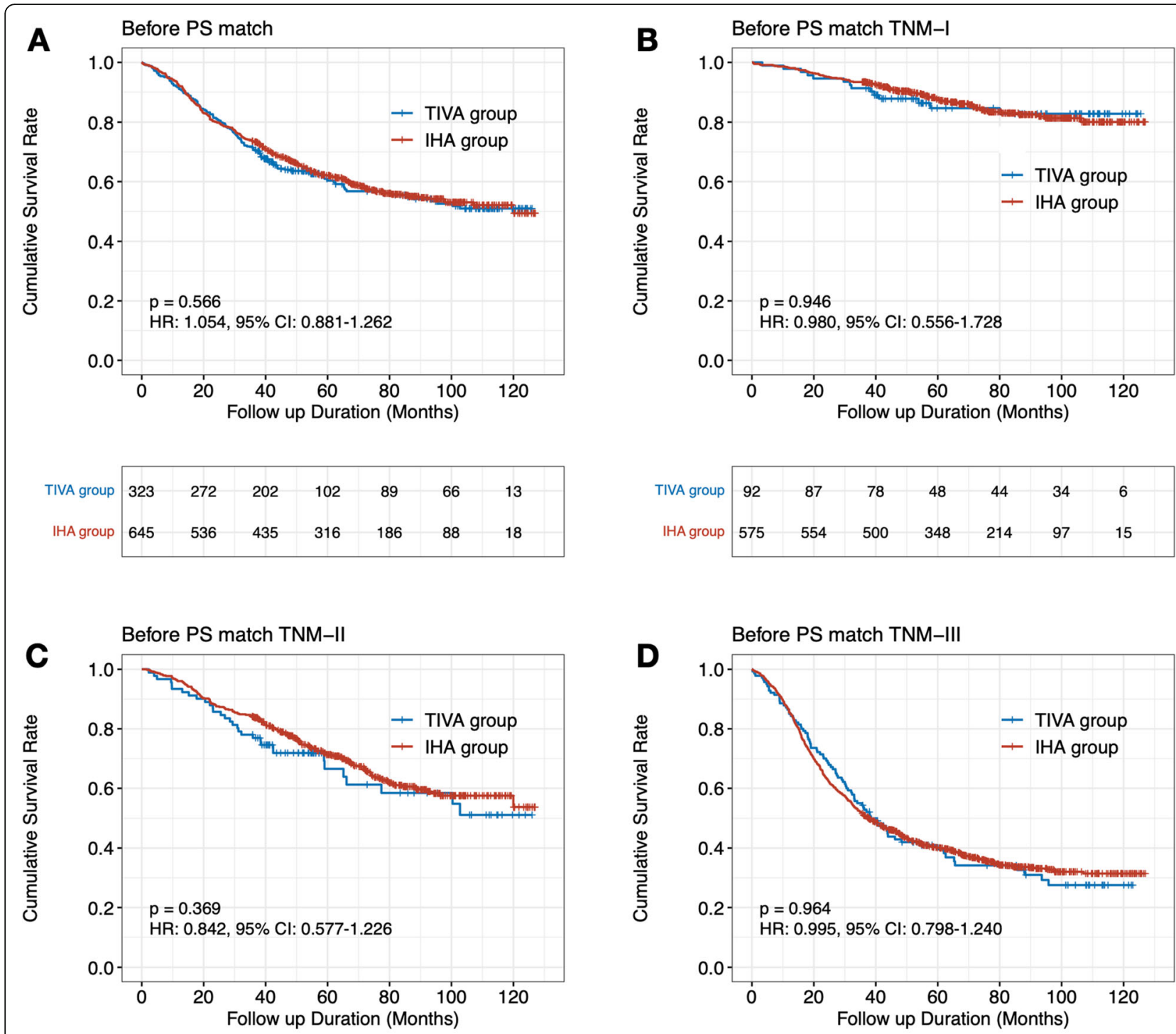

\begin{tabular}{|l|l|l|l|l|l|l|l|}
\cline { 2 - 8 } TIVA group & 91 & 82 & 62 & 25 & 21 & 16 & 3 \\
\hline IHA group & 529 & 478 & 407 & 280 & 157 & 65 & 14 \\
\hline
\end{tabular}

\begin{tabular}{|l|r|r|r|r|r|r|r|}
\hline TIVA group & 140 & 103 & 62 & 29 & 24 & 16 & 4 \\
\hline IHA group & 1160 & 812 & 536 & 360 & 181 & 71 & 20 \\
\hline
\end{tabular}

Fig. 3 Survival outcomes between TIVA and IHA groups and subgroup analyses before propensity-score matching cohorts (A. Survival rate for all TNM stages; B. Survival rate for TNM-I stage; C. Survival rate for TNM-II stage; D. Survival rate for TNM-III stage)

the survival rates of patients at each stage. Meanwhile, we performed a pooled analysis of survival results from previously reported studies and our study to explore whether anesthesia type can influence the survival outcomes of gastric cancer patients who underwent surgical treatment. A critical statistical value was found in the before and after PS matching cohort between the TIVA and IHA groups for overall survival outcomes.

Although other perioperative treatment modalities, such as radiotherapy, may also affect tumor metastasis, the relationship between anesthetic techniques and the prognosis of cancer patients is one of the core concerns during the process of making treatment strategy decisions for malignant diseases. Regional anesthesia, such as epidural anesthesia, has positive implications in the prevention of immunosuppression and in reducing inflammation during the surgical treatment of malignant diseases.

Volatile agents are the most common method of maintaining general anesthesia worldwide. TIVA is primarily administered by propofol as an induction and maintenance agent. Propofol has been shown in in vitro 

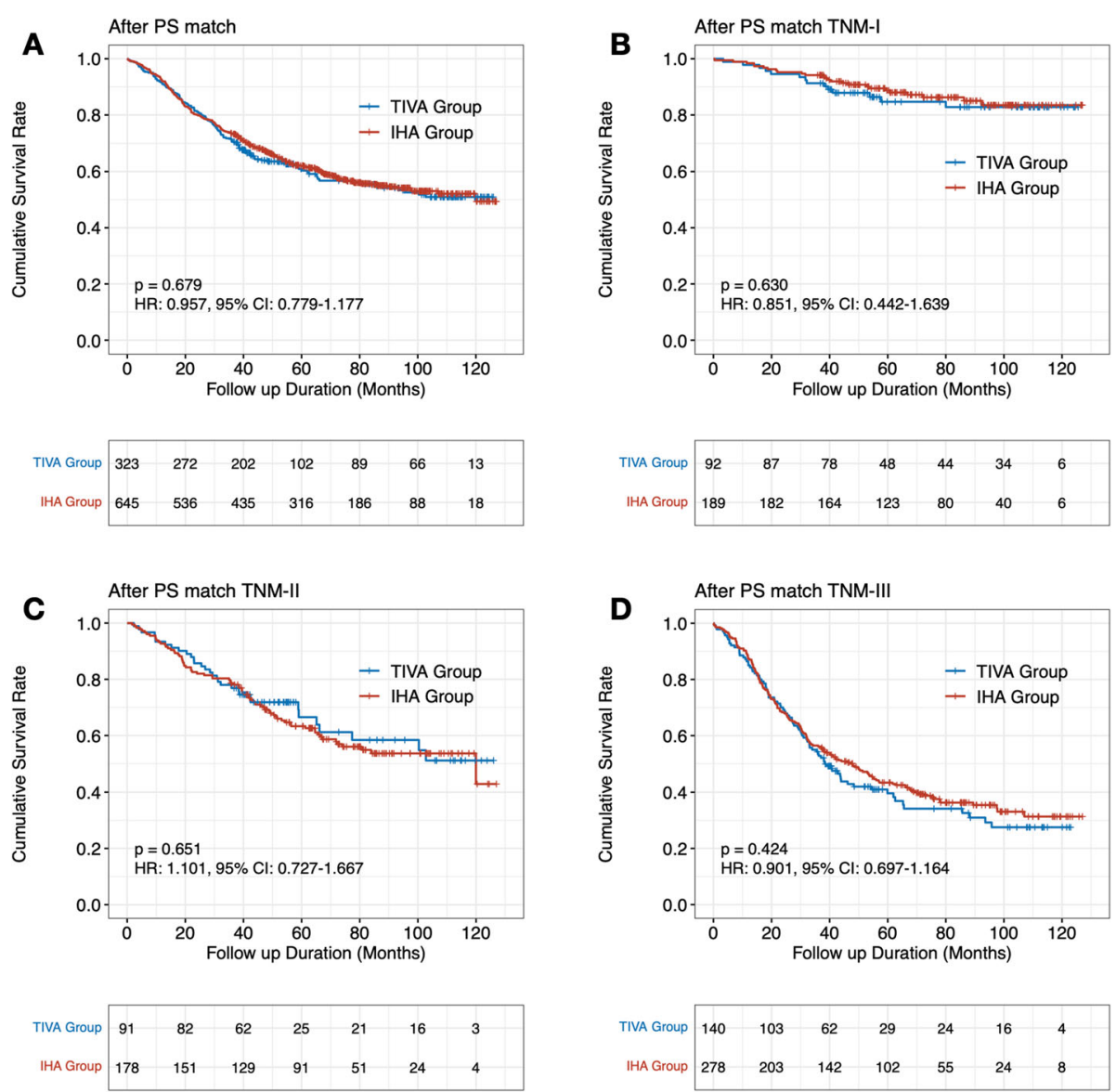

Fig. 4 Survival outcomes between TIVA and IHA groups and subgroup analyses in after propensity-score matching cohorts (A. Survival rate for all TNM stages; B. Survival rate for TNM-I stage; C. Survival rate for TNM-II stage; D. Survival rate for TNM-III stage)

Table 2 Univariate and Multivariate survival analysis of patients before propensity-score match $(N=2587)$

\begin{tabular}{|c|c|c|c|c|c|c|c|}
\hline \multirow[t]{2}{*}{ Characteristics } & & \multicolumn{3}{|c|}{ Univariate } & \multicolumn{3}{|c|}{ Multivariate } \\
\hline & & $\mathrm{HR}$ & $95 \% \mathrm{Cl}$ & $P$ value & HR & $95 \% \mathrm{Cl}$ & $P$ value \\
\hline Age, years & $<65$ vs. $\geq 65$ & 1.307 & $1.157-1.477$ & $<0.001$ & 1.217 & $1.075-1.379$ & 0.002 \\
\hline Gender & Male vs. Female & 0.998 & $0.879-1.133$ & 0.978 & & & \\
\hline Tumor location & AEG vs. Non-AEG & 0.723 & $0.638-0.819$ & $<0.001$ & 0.882 & $0.777-1.002$ & 0.054 \\
\hline Tumor size, cm & $<5$ vs. $\geq 5$ & 2.714 & $2.388-3.084$ & $<0.001$ & 1.352 & $1.168-1.566$ & $<0.001$ \\
\hline Macroscopic type & Type 0-2 vs. Type 3-4 & 2.080 & $1.850-2.338$ & $<0.001$ & 1.164 & $1.026-1.321$ & 0.019 \\
\hline Differentiate degree & G1-2 vs. G3 & 1.517 & $1.291-1.782$ & $<0.001$ & 1.105 & $0.935-1.306$ & 0.240 \\
\hline Radical degree & Ro vs. R1/R2 & 3.084 & $2.473-3.846$ & $<0.001$ & 1.920 & $1.534-2.404$ & $<0.001$ \\
\hline Lymphadenectomy degree & D1/D1+ vs. D2/D2+ & 1.035 & $0.869-1.232$ & 0.701 & & & \\
\hline \multirow[t]{2}{*}{ pTNM stage } & | vs. || & 2.601 & $2.048-3.304$ & $<0.001$ & 2.316 & $1.803-2.974$ & $<0.001$ \\
\hline & | vs. ||| & 6.519 & $5.284-8.042$ & $<0.001$ & 4.970 & $3.916-6.308$ & $<0.001$ \\
\hline Adjuvant chemotherapy & No vs. Yes & 0.884 & $0.786-0.995$ & 0.041 & 0.715 & $0.634-0.807$ & $<0.001$ \\
\hline Anesthesia method & IVA vs. IHA & 1.054 & $0.881-1.262$ & 0.566 & 0.932 & $0.778-1.116$ & 0.441 \\
\hline NSAIDs & No vs. Yes & 1.183 & $0.828-1.691$ & 0.355 & & & \\
\hline
\end{tabular}

Abbreviations: HR Hazard ratio, CI Confidence interval, AEG Adenocarcinoma of esophagogastric junction, TIVA Total intravenous anesthesia, IHA Inhalation anesthesia, NSAIDs Nonsteroidal Anti-inflammatory Drugs 
Table 3 Univariate and Multivariate survival analysis of patients after propensity-score match $(N=1032)$

\begin{tabular}{|c|c|c|c|c|c|c|c|}
\hline \multirow[t]{2}{*}{ Characteristics } & & \multicolumn{3}{|c|}{ Univariate } & \multicolumn{3}{|c|}{ Multivariate } \\
\hline & & $\overline{H R}$ & $95 \% \mathrm{Cl}$ & $P$ value & $\overline{H R}$ & $95 \% \mathrm{Cl}$ & $P$ value \\
\hline Age, years & $<65$ vs. $\geq 65$ & 1.462 & $1.198-1.785$ & $<0.001$ & 1.421 & $1.159-1.743$ & 0.001 \\
\hline Gender & Male vs. Female & 0.955 & $0.774-1.179$ & 0.669 & & & \\
\hline Tumor location & AEG vs. Non-AEG & 0.783 & $0.629-0.975$ & 0.029 & 1.006 & $0.802-1.261$ & 0.961 \\
\hline Tumor size, cm & $<5$ vs. $\geq 5$ & 2.513 & $2.052-3.077$ & $<0.001$ & 1.382 & $1.100-1.736$ & 0.005 \\
\hline Macroscopic Type & Type 0-2 vs. Type 3-4 & 1.963 & $1.615-2.386$ & $<0.001$ & 1.118 & $0.903-1.383$ & 0.306 \\
\hline Differentiate Degree & G1-2 vs. G3 & 1.407 & $1.077-1.837$ & 0.012 & 1.12 & $0.849-1.478$ & 0.422 \\
\hline Radical Degree & R0 vs. R1/R2 & 2.079 & $0.985-4.391$ & 0.055 & 1.367 & $0.644-2.905$ & 0.416 \\
\hline Lymphadenectomy degree & D1/D1+ vs. D2/D2+ & 1.220 & $0.883-1.686$ & 0.229 & & & \\
\hline \multirow[t]{2}{*}{ TNM stage } & | vs. || & 3.440 & $2.383-4.965$ & $<0.001$ & 3.214 & $2.197-4.703$ & $<0.001$ \\
\hline & | vs. ||| & 6.691 & $4.775-9.376$ & $<0.001$ & 5.569 & $3.834-8.089$ & $<0.001$ \\
\hline Adjuvant Chemotherapy & No vs. Yes & 0.833 & $0.685-1.013$ & 0.068 & 0.693 & $0.567-0.847$ & $<0.001$ \\
\hline Anesthesia method & IVA vs. IHA & 0.957 & $0.779-1.177$ & 0.679 & 0.946 & $0.769-1.163$ & 0.597 \\
\hline NSAIDS & No vs. Yes & 0.574 & $0.256-1.285$ & 0.177 & & & \\
\hline
\end{tabular}

Abbreviations: HR Hazard ratio, Cl Confidence interval, AEG Adenocarcinoma of esophagogastric junction, TIVA Total intravenous anesthesia, IHA Inhalation anesthesia, NSAIDs Nonsteroidal Anti-inflammatory Drugs

experiments to inhibit the expression of oncogenes and suppress tumor angiogenesis, resulting in a lower recurrence rate [21-24].

The survival impact of anesthetic and anesthesia type used during the operation has been evaluated in several malignant diseases. Total intravenous anesthesia has been found to be associated with significantly better survival outcomes than inhalation anesthesia for esophageal cancer patients [25]. In addition, in a large sample size study of colon cancer patients, total intravenous anesthesia had better survival outcomes than inhalation anesthesia irrespective of the tumor-node-metastasis stage [11]. However, for patients who underwent breast cancer surgery, contradictory results were found in previous studies. A study showed that propofol-based TIVA had a lower tumor recurrence risk than sevofluranebased IHA for breast cancer patients [26]. However, another existing studies found no significant difference in disease-free survival and overall survival between TIVA and IHA for breast cancer patients [12, 27]. Tumor

Table 4 General characteristics of study compare survival outcomes between total intravenous and inhalation anesthesia

\begin{tabular}{|c|c|c|c|c|c|c|c|c|c|c|c|c|c|}
\hline \multirow[t]{2}{*}{ Author } & \multirow[t]{2}{*}{ Country } & \multirow[t]{2}{*}{$\begin{array}{l}\text { Time } \\
\text { Period }\end{array}$} & \multirow[t]{2}{*}{$\begin{array}{l}\text { Tumor } \\
\text { Stage }\end{array}$} & \multirow[t]{2}{*}{$\begin{array}{l}\text { Operation } \\
\text { Type }\end{array}$} & \multirow[t]{2}{*}{$\begin{array}{l}\text { Match } \\
\text { method }\end{array}$} & \multirow[t]{2}{*}{$\begin{array}{l}\text { PS } \\
\text { match }\end{array}$} & \multicolumn{2}{|c|}{$\begin{array}{l}\text { No. of } \\
\text { Patients }\end{array}$} & \multicolumn{2}{|l|}{ Age (year) } & \multicolumn{2}{|c|}{$\begin{array}{l}\text { Gender } \\
\text { (male) }\end{array}$} & \multirow{2}{*}{$\begin{array}{l}\text { Survival } \\
\text { outcome } \\
\text { HR }(95 \% \mathrm{CI}) \\
\text { IVA vs. IHA }\end{array}$} \\
\hline & & & & & & & TIVA & IHA & IVA & IHA & IVA & IHA & \\
\hline \multirow[t]{2}{*}{$\begin{array}{l}\text { Oh et al., } \\
2019\end{array}$} & \multirow[t]{2}{*}{ Korea } & \multirow[t]{2}{*}{$\begin{array}{l}2005- \\
2015\end{array}$} & \multirow{2}{*}{$\begin{array}{l}\text { I-III } \\
\text { AJCC } \\
7 \text { th }\end{array}$} & \multirow[t]{2}{*}{$\begin{array}{l}\text { Lap and } \\
\text { Open }\end{array}$} & \multirow[t]{2}{*}{$\begin{array}{l}\text { 1:1 PS } \\
\text { match }\end{array}$} & Before & 816 & 3791 & $58.3 \pm 12.4$ & $60.5 \pm 12.7$ & 564 & 2511 & $\begin{array}{l}0.57(0.37- \\
0.88)\end{array}$ \\
\hline & & & & & & After & 769 & 769 & $58.7 \pm 12.4$ & $59.3 \pm 12.7$ & 527 & 527 & $\begin{array}{l}0.92(0.52- \\
1.63)\end{array}$ \\
\hline \multirow[t]{2}{*}{$\begin{array}{l}\text { Zheng et al., } \\
2018\end{array}$} & \multirow[t]{2}{*}{ China } & \multirow[t]{2}{*}{$\begin{array}{l}2007- \\
2012\end{array}$} & \multirow{2}{*}{$\begin{array}{l}\text { I-III } \\
\text { AJCC } \\
7 \text { th }\end{array}$} & \multirow[t]{2}{*}{$\begin{array}{l}\text { Open } \\
\text { Surgery }\end{array}$} & \multirow[t]{2}{*}{$\begin{array}{l}1: 1 \text { PS } \\
\text { match }\end{array}$} & Before & 1506 & 1350 & NA & NA & 313 & 317 & $\begin{array}{l}0.61(0.54- \\
0.68)\end{array}$ \\
\hline & & & & & & After & 897 & 897 & NA & NA & 159 & 160 & $\begin{array}{l}0.65(0.56- \\
0.75)\end{array}$ \\
\hline \multirow[t]{2}{*}{$\begin{array}{l}\text { Huang et al., } \\
2019\end{array}$} & \multirow[t]{2}{*}{ China } & \multirow[t]{2}{*}{$\begin{array}{l}2006- \\
2016\end{array}$} & \multirow[t]{2}{*}{ I-IV } & \multirow[t]{2}{*}{$\begin{array}{l}\text { Not } \\
\text { mentioned }\end{array}$} & \multirow[t]{2}{*}{$\begin{array}{l}1: 1 \mathrm{PS} \\
\text { match }\end{array}$} & Before & 190 & 218 & $65 \pm 14$ & $66 \pm 15$ & 124 & 150 & $\begin{array}{l}0.47(0.34- \\
0.63)\end{array}$ \\
\hline & & & & & & After & 167 & 167 & $66 \pm 14$ & $65 \pm 15$ & 114 & 116 & $\begin{array}{l}0.56(0.41- \\
0.78)\end{array}$ \\
\hline \multirow[t]{2}{*}{ Wu et al.* } & \multirow[t]{2}{*}{ China } & \multirow[t]{2}{*}{$\begin{array}{l}2009- \\
2016\end{array}$} & \multirow{2}{*}{$\begin{array}{l}|-||| \\
\text { AJCC } \\
\text { 8th }\end{array}$} & \multirow[t]{2}{*}{$\begin{array}{l}\text { Lap and } \\
\text { Open }\end{array}$} & \multirow[t]{2}{*}{$\begin{array}{l}1: 2 \text { PS } \\
\text { match }\end{array}$} & Before & 323 & 2264 & $\begin{array}{l}60.0[51.0 \\
66.0]\end{array}$ & $\begin{array}{l}59.00[50.0 \\
66.0]\end{array}$ & 221 & 1593 & $\begin{array}{l}1.05(0.88- \\
1.26)\end{array}$ \\
\hline & & & & & & After & 323 & 645 & $\begin{array}{l}60.0[51.0, \\
66.0]\end{array}$ & $\begin{array}{l}60.0[51.0, \\
67.0]\end{array}$ & 221 & 440 & $\begin{array}{l}0.96(0.78- \\
1.18)\end{array}$ \\
\hline
\end{tabular}




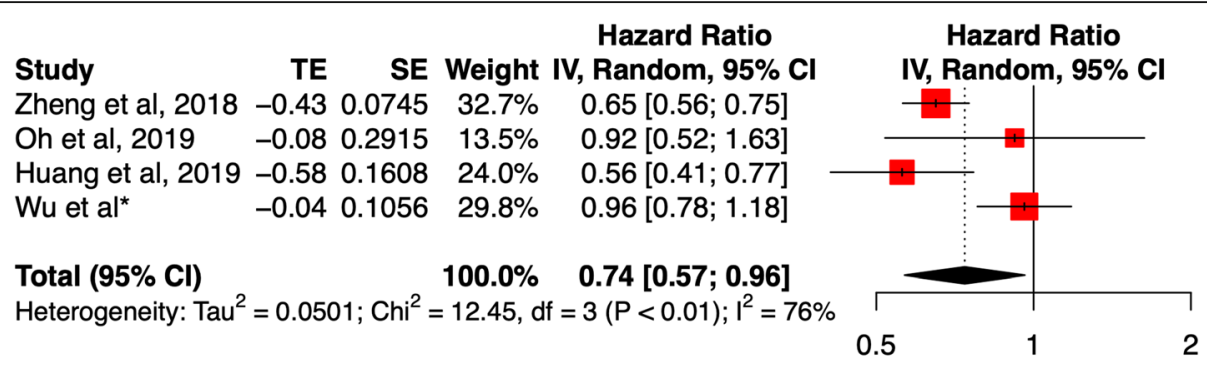

A

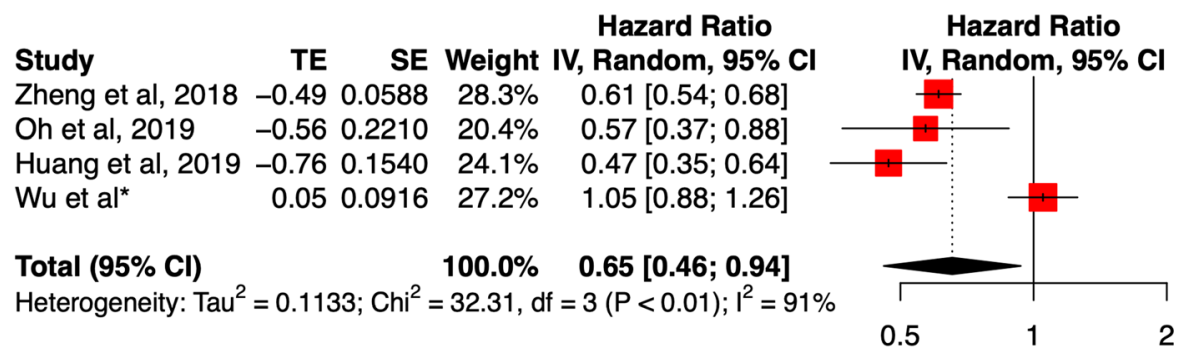

B

Fig. 5 Forest plot of survival outcomes among study compares intravenous anesthesia and inhalation anesthesia (A. Before propensity score matching, B. After propensity score matching)

heterogeneity and molecular characteristics are important explanations for the differential treatment outcomes of cancer patients $[28,29]$. Whether these factors can help explain the different results among the different cancer types with total intravenous anesthesia or inhalation anesthesia is unclear. Therefore, not only is there a need for research on the relationship and mechanism of anesthetic drugs and the immunological response, further study is expecting to analyze the effects of anesthetic drugs on the expression levels of oncogenes or the regulation of the tumor microenvironment, corresponding functional changes of tumor biological behavior, and the survival outcomes of cancer patients.

Specific to gastric cancer, only three studies have reported the influence of TIVA or IHA on the survival outcomes of surgical treatment [14-16]. Although these studies both used the PS matching method to balance clinicopathological characteristics, their conclusions were very different. Different tumor stages or surgical treatment strategies might be the reasons for the different survival outcomes between these two studies. For example, in the study of Oh et al., more than half of the patients underwent laparoscopic surgery, whereas patients who underwent laparoscopic surgery were excluded from the study of Zheng et al. [14, 15]. Laparoscopic gastric cancer surgery has a lower risk of adverse inflammatory reactions than open surgery [30]. Therefore, a reduction of adverse immune reactions by a high proportion of laparoscopic surgeries may amplify the effect of inhalation anesthesia on immune suppression.

In our study, we did not exclude laparoscopic surgery and found no survival difference between total intravenous anesthesia and inhalation anesthesia with long-term follow-up. In addition, the different follow-up durations may be another reason for the different survival results of the previous two studies. The limited follow-up duration of the study of Oh et al. may not fully and accurately reflect the survival difference between the TIVA and IHA groups. Our study balanced the operation type (laparoscopic and open operations) and analyzed longterm survival outcomes. Therefore, according to the results of our study, both TIVA and IHA are acceptable anesthesia methods for gastric cancer surgery.

In addition, the contradictory survival results reported for TIVA and IHA used to treat gastric cancers should be considered. We performed a meta-analysis of survival outcomes between total intravenous anesthesia and inhalation anesthesia, including data from previously reported studies and our study. However, there was a significant difference in survival between the TIVA and IHA groups in the meta-analysis. What calls for special attention is that all three studies included in the metaanalysis were retrospective studies, and selection bias and other natural limitations of the retrospective study design cannot be neglected. Therefore, these results have limited reference value for clinical indications of the choice of anesthesia type. According to the present 
clinical evidence, the selection of total intravenous anesthesia or inhalation anesthesia should be made according to the individualized situation of each patient.

Limitations of all retrospective studies should also be considered when interpreting the results of the present study. First, we adopted the PS matching method, but selection bias in the choice of anesthesia type cannot be neglected. Second, the sample size of the present study was based on the data available during the study period rather than calculated in advance as in a prospective study. There exists the potential of an inadequate sample size and statistical power, which cannot detect a significant difference between the two anesthesia types. Third, recurrence type data were not completely collected in the present study. Therefore, the relationship of TIVA and IHA with recurrence type or recurrence-free survival outcomes was not analyzed. Finally, due to the limitations of the retrospective design, inflammatory markers were not measured, and we could not explain the relationship between the inflammatory response and types of anesthesia used for gastric cancer surgery.

\section{Conclusions}

In conclusion, combined with the results of previous studies, total intravenous anesthesia has been shown to be superior to inhalation anesthesia in terms of overall survival for gastric cancer patients undergoing surgical treatment. The selection of intravenous or inhalation anesthesia for gastric cancer surgery should take into account the long-term prognosis of the patient.

\section{Abbreviations}

TIVA: Total intravenous anesthesia; IHA: Inhalation anesthesia; PS: Propensity score; AEG: Adenocarcinoma of the esophagogastric junction; NSAI

Ds: Nonsteroidal anti-inflammatory drugs; SD: Standard deviation; HR: Hazard ratio; 95\% Cl: 95\% confidence intervals; IQR: Interquartile range;

PS: Propensity score; SMD: Standardized mean difference

\section{Supplementary Information}

The online version contains supplementary material available at https://doi. org/10.1186/s12885-021-08946-7.

Additional file 1: Supplementary Figure 1. Flow diagram of study selection (PRISMA format).

\section{Acknowledgments}

The authors thank the volunteer team of gastric cancer surgery (VOLTGA) for the substantial work based on the multidisciplinary team (MDT) of gastric cancer, West China Hospital, Sichuan University, China.

\section{Authors' contributions}

Tao Zhu and Jian-Kun Hu designed the study; Wei-Wei Wu, Wei-Han Zhang, Kai Liu and Xin-Zu Chen collected information; Wei-Wei Wu and Wei-Han Zhang analyzed and interpreted data; Zong-Guang Zhou, Jin Liu, Tao Zhu and Jian-Kun Hu supervised this study; All authors contributed to the writing of the manuscript and final approval.

\section{Funding}

1) National Natural Science Foundation of China (no.81902437)
2) 1.3.5 project for disciplines of excellence, West China hospital, Sichuan University (no. ZYJC21006)

3) Post-doctor research project, West China hospital, Sichuan University (2018HXBH010)

4) Project funded by China Postdoctoral Science Foundation (2019 M653418, 2020 T130449)

5) Department of Sichuan Science \& technology program (20YYJC3357, 2021YJ0475)

\section{Availability of data and materials}

Data supporting the findings of this study are available from the corresponding author upon reasonable request.

\section{Declarations}

All methods of this study were carried out in accordance with relevant guidelines and regulations.

\section{Ethics approval and consent to participate}

We collected data from the database of the Surgical Gastric Cancer Patient Registry in West China Hospital with the registration number WCH-SGCPR2020. The approval to access and use the dataset was obtained from the Biomedical Ethical Committee of the West China Hospital, Sichuan University, China (No. 2014-215). Patient records and personal information were deidentified before statistical analysis.

\section{Consent for publication}

Written informed consent for publication was obtained from all participants, subjects under 16 years of age were not included in this trial.

\section{Competing interests}

The authors declare no competing interests.

\section{Author details}

'Department of Anesthesiology, West China Hospital, Sichuan University, No. 37 Guo Xue Street, Chengdu, Sichuan Province, China. ${ }^{2}$ Department of Gastrointestinal Surgery and Laboratory of Gastric Cancer, State Key Laboratory of Biotherapy, West China Hospital, Sichuan University, and Collaborative Innovation Center for Biotherapy, No. 37 Guo Xue Street, Chengdu, Sichuan Province, China.

Received: 6 June 2021 Accepted: 14 October 2021

Published online: 10 November 2021

\section{References}

1. Global Burden of Disease Cancer C, Fitzmaurice C, Abate D, Abbasi N, Abbastabar H, Abd-Allah F, et al. Global, Regional, and National Cancer Incidence, Mortality, Years of Life Lost, Years Lived With Disability, and Disability-Adjusted Life-Years for 29 Cancer Groups, 1990 to 2017: A systematic analysis for the global burden of disease study. JAMA Oncol. 2019;5(12):1749-68.

2. Chen W, Zheng R, Baade PD, Zhang S, Zeng H, Bray F, et al. Cancer statistics in China, 2015. CA Cancer J Clin. 2016;66(2):115-32. https://doi.org/10.3322/ caac. 21338 .

3. Japanese Gastric Cancer A. Japanese gastric cancer treatment guidelines 2014 (ver. 4). Gastric Cancer. 20(1):1-19. https://doi.org/10.1007/s10120-0160622-4.

4. Japanese Gastric Cancer A. Japanese gastric cancer treatment guidelines 2018 (5th edition). Gastric Cancer. 2020;24(1):1-21.

5. Han DS, Suh YS, Kong SH, Lee HJ, Choi Y, Aikou S, et al. Nomogram predicting long-term survival after d2 gastrectomy for gastric cancer. J Clin Oncol. 2012;30(31):3834-40. https://doi.org/10.1200/JCO.2012.41.8343.

6. Shu Y, Zhang W, Hou Q, Zhao L, Zhang S, Zhou J, et al. Prognostic significance of frequent CLDN18-ARHGAP26/6 fusion in gastric signet-ring cell cancer. Nat Commun. 2018;9(1):2447. https://doi.org/10.1038/s41467-01 8-04907-0.

7. Kurosawa S, Kato M. Anesthetics, immune cells, and immune responses. Anesth. 2008;22(3):263-77. https://doi.org/10.1007/s00540-008-0626-2.

8. Melamed R, Bar-Yosef S, Shakhar G, Shakhar K, Ben-Eliyahu S. Suppression of natural killer cell activity and promotion of tumor metastasis by ketamine, thiopental, and halothane, but not by propofol: mediating mechanisms and 
prophylactic measures. Anesth Analg. 2003;97(5):1331-9. https://doi.org/1 0.1213/01.ANE.0000082995.44040.07.

9. Buckley A, McQuaid S, Johnson P, Buggy DJ. Effect of anaesthetic technique on the natural killer cell anti-tumour activity of serum from women undergoing breast cancer surgery: a pilot study. Br J Anaesth. 2014; 113(Suppl 1):i56-62. https://doi.org/10.1093/bja/aeu200.

10. Lai HC, Lee MS, Lin KT, Huang YH, Chen JY, Lin YT, et al. Propofolbased total intravenous anesthesia is associated with better survival than desflurane anesthesia in robot-assisted radical prostatectomy. PLoS ONE. 2020;15(3):e0230290. https://doi.org/10.1371/journal.pone. 0230290.

11. Wu ZF, Lee MS, Wong CS, Lu CH, Huang YS, Lin KT, et al. Propofol-based Total intravenous anesthesia is associated with better survival than Desflurane anesthesia in Colon Cancer surgery. Anesthesiology. 2018;129(5): 932-41. https://doi.org/10.1097/ALN.0000000000002357.

12. Yoo S, Lee HB, Han W, Noh DY, Park SK, Kim WH, et al. Total intravenous anesthesia versus inhalation anesthesia for breast Cancer surgery: a retrospective cohort study. Anesthesiology. 2019;130(1):31-40. https://doi. org/10.1097/ALN.0000000000002491.

13. Huang YH, Lee MS, Lou YS, Lai HC, Yu JC, Lu CH, et al. Propofol-based total intravenous anesthesia did not improve survival compared to desflurane anesthesia in breast cancer surgery. PLoS ONE. 2019;14(11):e0224728. https://doi.org/10.1371/journal.pone.0224728.

14. Zheng $X$, Wang $Y$, Dong $L$, Zhao S, Wang $L$, Chen $H$, et al. Effects of propofol-based total intravenous anesthesia on gastric cancer: a retrospective study. Onco Targets Ther. 2018;11:1141-8. https://doi.org/1 0.2147/OTT.S156792.

15. Oh TK, Kim HH, Jeon YT. Retrospective analysis of 1-year mortality after gastric cancer surgery: Total intravenous anesthesia versus volatile anesthesia. Acta Anaesthesiol Scand. 2019;63(9):1169-77. https://doi.org/1 0.1111 /aas. 13414 .

16. Huang NC, Lee MS, Lai HC, Lin HT, Huang YH, Lu CH, et al. Propofol-based total intravenous anesthesia improves survival compared to desflurane anesthesia in gastric cancer surgery: a retrospective analysis. Medicine (Baltimore). 2020;99(25):e20714. https://doi.org/10.1097/MD.000000000002 0714.

17. Chen HN, Shu Y, Liao F, Liao X, Zhang H, Qin Y, et al. Genomic evolution and diverse models of systemic metastases in colorectal cancer. Gut. 2021: gutjpl-2020-323703. https://doi.org/10.1136/gutjnl-2020-323703.

18. Zhang WH, Chen XZ, Liu K, Chen XL, Yang K, Zhang B, et al. Outcomes of surgical treatment for gastric cancer patients: 11-year experience of a Chinese high-volume hospital. Med Oncol. 2014;31(9):150. https://doi.org/1 0.1007/s12032-014-0150-1.

19. Amin MB, Edge SB, Greene FL, et al. AJCC Cancer Staging Manual. 8th ed. NewYork: Springer; 2017.

20. Austin PC. Optimal caliper widths for propensity-score matching when estimating differences in means and differences in proportions in observational studies. Pharm Stat. 2011;10(2):150-61. https://doi.org/10.1 002/pst.433

21. Du Q, Liu J, Zhang X, Zhang X, Zhu H, Wei M, et al. Propofol inhibits proliferation, migration, and invasion but promotes apoptosis by regulation of Sox4 in endometrial cancer cells. Braz J Med Biol Res. 2018;51(4):e6803. https://doi.org/10.1590/1414-431×20176803.

22. Fei G, Cao M, Ge C, Cui L. Propofol suppresses hepatocellular carcinoma by inhibiting NET1 through downregulating ERKNEGF signaling pathway. Sci Rep. 2020;10(1):11208. https://doi.org/10.1038/s41598-020-67693-0.

23. Huang $\mathrm{H}$, Benzonana LL, Zhao H, Watts HR, Perry NJ, Bevan C, et al. Prostate cancer cell malignancy via modulation of HIF-1alpha pathway with isoflurane and propofol alone and in combination. Br J Cancer. 2014;111(7): 1338-49. https://doi.org/10.1038/bjc.2014.426.

24. Zhou CL, Li JJ, Ji P. Propofol suppresses esophageal squamous cell carcinoma cell migration and invasion by Down-regulation of sexdetermining region Y-box 4 (SOX4). Med Sci Monit. 2017;23:419-27. https:// doi.org/10.12659/MSM.899732.

25. Jun IJ, Jo JY, Kim Jl, Chin JH, Kim WJ, Kim HR, et al. Impact of anesthetic agents on overall and recurrence-free survival in patients undergoing esophageal cancer surgery: a retrospective observational study. Sci Rep. 2017:7(1):14020. https://doi.org/10.1038/s41598-017-14147-9.

26. Lee JH, Kang SH, Kim Y, Kim HA, Kim BS. Effects of propofol-based total intravenous anesthesia on recurrence and overall survival in patients after modified radical mastectomy: a retrospective study. Korean J Anesthesiol. 2016;69(2):126-32. https://doi.org/10.4097/kjae.2016.69.2.126.

27. Kim MH, Kim DW, Kim JH, Lee KY, Park S, Yoo YC. Does the type of anesthesia really affect the recurrence-free survival after breast cancer surgery? Oncotarget. 2017;8(52):90477-87. https://doi.org/10.18632/oncota rget.21014.

28. Hoadley KA, Yau C, Hinoue T, Wolf DM, Lazar AJ, Drill E, et al. Cell-of-origin patterns dominate the molecular classification of 10,000 tumors from 33 types of Cancer. Cell. 2018;173(2):291-304 e296. https://doi.org/10.1016/j. cell.2018.03.022.

29. Caswell DR, Swanton C. The role of tumour heterogeneity and clonal cooperativity in metastasis, immune evasion and clinical outcome. BMC Med. 2017;15(1):133. https://doi.org/10.1186/s12916-017-0900-y.

30. Shu ZB, Cao HP, Li YC, Sun LB. Influences of laparoscopic-assisted gastrectomy and open gastrectomy on serum interleukin-6 levels in patients with gastric cancer among Asian populations: a systematic review. BMC Gastroenterol. 2015;15(1):52. https://doi.org/10.1186/s12876-015-0276-4.

\section{Publisher's Note}

Springer Nature remains neutral with regard to jurisdictional claims in published maps and institutional affiliations.

Ready to submit your research? Choose BMC and benefit from:

- fast, convenient online submission

- thorough peer review by experienced researchers in your field

- rapid publication on acceptance

- support for research data, including large and complex data types

- gold Open Access which fosters wider collaboration and increased citations

- maximum visibility for your research: over $100 \mathrm{M}$ website views per year

At BMC, research is always in progress.

Learn more biomedcentral.com/submissions 